\title{
PHARMACOGNOSTICAL STANDARDIZATION OF RHIZOMES OF NUPHAR LUTEUM
}

MANPREET KAUR $^{1 *}$, HAYAT M MUKHTAR ${ }^{2}$

${ }^{1}$ Department of Pharmaceutical Sciences (Pharmacognosy), G.H.G Khalsa College of Pharmacy, Gurusar Sadhar - 141 104, Ludhiana, Punjab, India. '2Department of Pharmaceutical Sciences (Pharmacognosy), Shaheed Bhagat Singh College of Pharmacy, Patti, Tarn Taran, Amritsar, Punjab. India. Email: asrpreet2007@rediffmail.com

Received: 08 April 2017, Revised and Accepted: 09 February 2017

ABSTRACT

Objective: This study provides the detailed summary of pharmacognostical characters of rhizomes to give clear standards for the identification of drug.

Methods: Important details such as macroscopy, microscopy (transverse section [TS] and powder microscopy) along with physico-chemical parameters (such as loss on drying, ash values, and extractive values), and quantitative studies (i.e foreign matter, length and width of xylem vessels and calcium oxalate crystals, and diameter of starch grains) were performed by standard procedure.

Results: The findings of macroscopic studies revealed that the rhizomes were internally creamish to light brown and dark brown externally with longitudinal wrinkles. TS and powder microscopy of rhizomes showed the presence of fragments of cork, cellulosic parenchyma; scalariform type xylem vessels, fragments of ligneous parenchyma, lignified astrosclereids, and small ovoid, and rounded starch grains. The mean length and mean width of xylem vessels and calcium oxalate crystals were found to be $406 \mu \mathrm{m}$ (micrometer) and $60.2 \mu \mathrm{m}$ and $63.36 \mu \mathrm{m}$ and $48.96 \mu \mathrm{m}$. Whereas mean diameter of starch grains was $34.56 \mu$. Physicochemical standards quantified were foreign organic matter $(0.2 \%)$, total ash (12.3\%), acid insoluble ash (6.3\%), water soluble ash (3\%), loss on drying (12.5\%), alcohol-soluble extractive value (32.6\%), and water soluble extractive value (27.6\%)

Conclusion: As various pharmacognostical and physico-chemical parameters have pivotal roles in authentication, identification and establishments of quality parameters of the plant. This study was conducted for this purpose.

Keywords: Nuphar luteum, Nymphaeaceae, Pharmacognostical, Physicochemical.

(C) 2017 The Authors. Published by Innovare Academic Sciences Pvt Ltd. This is an open access article under the CC BY license (http://creativecommons. org/licenses/by/4. 0/) DOI: http://dx.doi.org/10.22159/ajpcr.2017.v10i8.19030

\section{INTRODUCTION}

Nuphar luteum (yellow water lily) is an aquatic plant of the family Nymphaeaceae, native to temperate regions of Europe, Northwest Africa, and Western Asia [1]. The dry rhizomes of N. luteum have yielded three sulfur-containing alkaloids: Thiobinupharidine, neothiobinupharidine, and nuphaleine (C30H4204N2S) [2]. The root is astringent, demulcent, and anodyne. Alcoholic extracts of $N$. luteum exhibits strong antibacterial and tumor inhibiting properties [3]. From the review of literature of the plant, it was found that no work was carried out on pharmacognostical standardization of rhizomes of the plant. This study aimed at evaluating the physicochemical properties and anatomical features of the rhizomes of the plant. The findings of this research would, therefore, be instrumental in creating a monograph of N. luteum plant.

\section{METHODS}

\section{Collection and preparation}

The rhizomes of $N$. luteum were purchased from Natural Botanicals Ghaziabad in July 2013 and were authenticated by the Dr. Sunita Garg, Chief Scientist of CSIR-NISCAIR, New Delhi with Ref.No.NISCAIR/ RHMD/consult/2013/2287/67. A voucher specimen (NL-1) was deposited in the departmental herbarium of G.H.G Khalsa College of Pharmacy, Gurusar Sadhar, Ludhiana, Punjab. The rhizomes were dried in the shade and coarsely powdered [4,5].

\section{Chemicals and reagents}

All chemicals were used of analytical grade and reagents were prepared in the distilled water. Reagents such as chloral hydrate, glycerine, clove oil, canada balsam, safranin solution, fast green, phloroglucinol, hydrochloric acid, lactophenol, and iodine solution were used for the studies.
Macroscopic and microscopic studies

The macroscopical characters of the root were studied by following standard methods [6]. The powder was rubbed slowly between fingers and odour was examined. Taste of the powder was also checked. Surface and fracture of root and rhizomes were touched and observed to determine whether it was soft or hard. Transverse section (TS) of root and rhizome and powder characteristics were identified with routine reagents such as chloral hydrate, glycerine, safranin solution, fast green, phloroglucinol, hydrochloric acid, lactophenol and iodine solution to study the lignified cells, fibre, xylem vessels, starch grains, and calcium oxalate crystal. Permanent slide of TS of root was prepared to observe the presence and arrangement of cellular structures as per the procedure of Johansen [7] and the representative figures were taken with the help microscopic image camera.

Physico-chemical parameters

The ash values including total ash, acid insoluble ash and water soluble ash and moisture content using the loss on drying method were determined as per the Indian Pharmacopoeia [8]. Extractive values with various solvents such as alcohol and water were performed as per standard procedure [9].

\section{Quantitative studies}

Foreign organic matter, length and width of xylem vessels, calcium oxalate crystals and diameter of starch grains, etc., were noted as per standard procedures $[10,11]$.

\section{RESULTS AND DISCUSSION}

Macroscopy

The colour of pieces of rhizomes was internally creamish to light brown and dark brown externally with longitudinal wrinkles. Odour was 
disagreeable with a bitter taste. Shape was cylindrical to irregular with variable size. Fracture was soft and brittle. Texture of upper surface was slightly rough (Plate 1 ).

\section{Microscopy}

After preparation of slide using chloral hydrate and glycerine and examine under microscope fragments of cork, cellulosic parenchyma; scalariform type xylem vessels and astrosclereids were observed. When stained with phloroglucinol and hydrochloric acid fragments of ligneous parenchyma, lignified astrosclereids and vessels were seen. When the powdered drug was cleared with chloral hydrate and mounted in lactophenol followed by iodine solution showed small ovoid and rounded starch grains. TS of the rhizome showed the presence of cork, cortex, pericyclic fiber, starch grains embedded in cells, and astrosclereids in the center portion or pith (as shown in Figs. 1-8). The results of quantitative microscopy are depicted in Table 1.

Standardization is the key for safety and efficacy of herbal preparations, and this can be achieved only by pharmacognostic

Table 1: Results of quantitative microscopy

\begin{tabular}{|c|c|c|c|}
\hline Parameter & Mean length & Mean width & $\begin{array}{l}\text { Mean } \\
\text { diameter }\end{array}$ \\
\hline Xylem vessels & $406 \mu \mathrm{m}$ & $60.2 \mu \mathrm{m}$ & \\
\hline Calcium oxalate crystals & $63.36 \mu \mathrm{m}$ & $48.96 \mu \mathrm{m}$ & \\
\hline Starch grains & & & $34.56 \mu \mathrm{m}$ \\
\hline
\end{tabular}

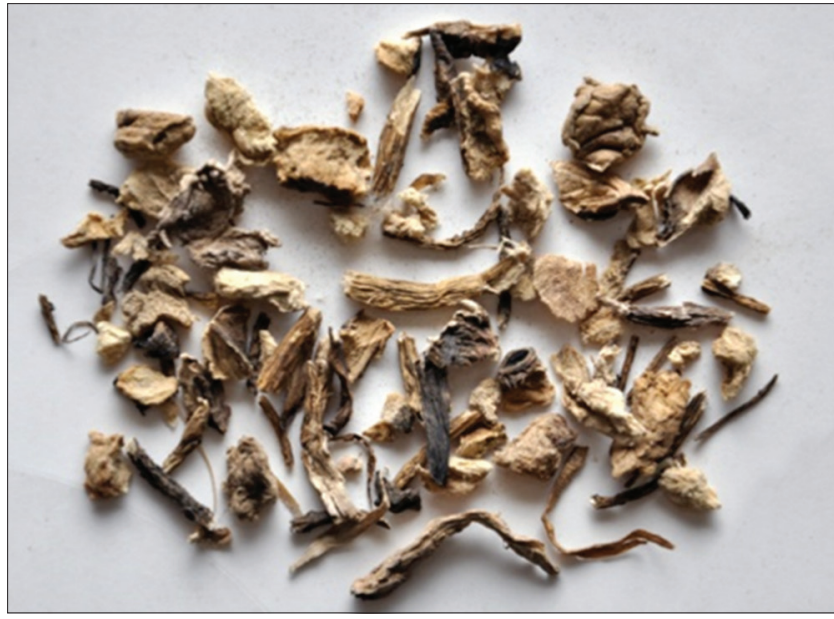

Plate 1: Photograph of rhizomes of Nuphar luteum

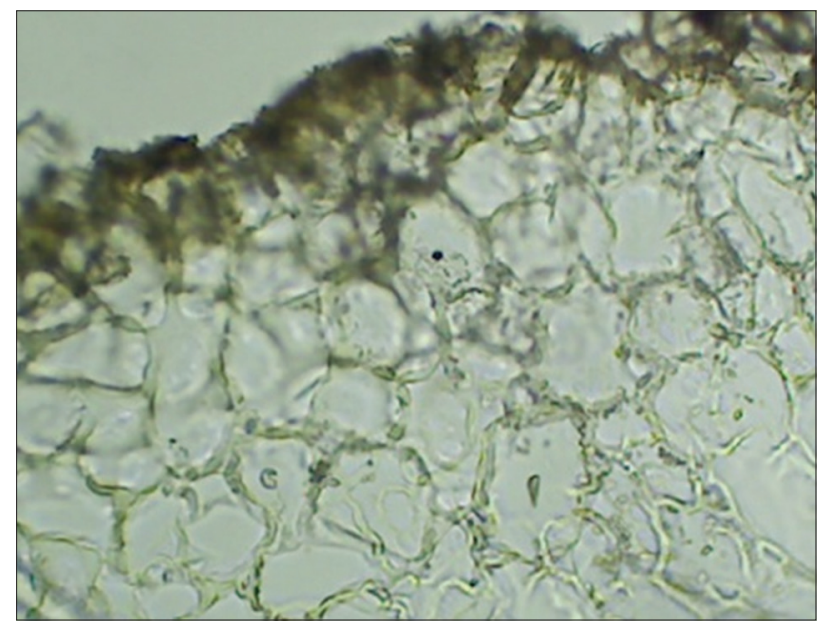

Fig. 1: Transverse section of rhizome showing cork studies. On the basis of these studies, identification and authentication of herbal drugs have become more appropriate which is also helpful for making monograph of plants. As per quantitative studies, foreign organic matter was found to be $0.2 \%$. Total ash, acid insoluble ash, and water soluble ash were found to be $12.3 \%, 6.3 \%$, and $3 \%$. The physicochemical constants are particularly important in the evaluation of purity of crude drugs [12].

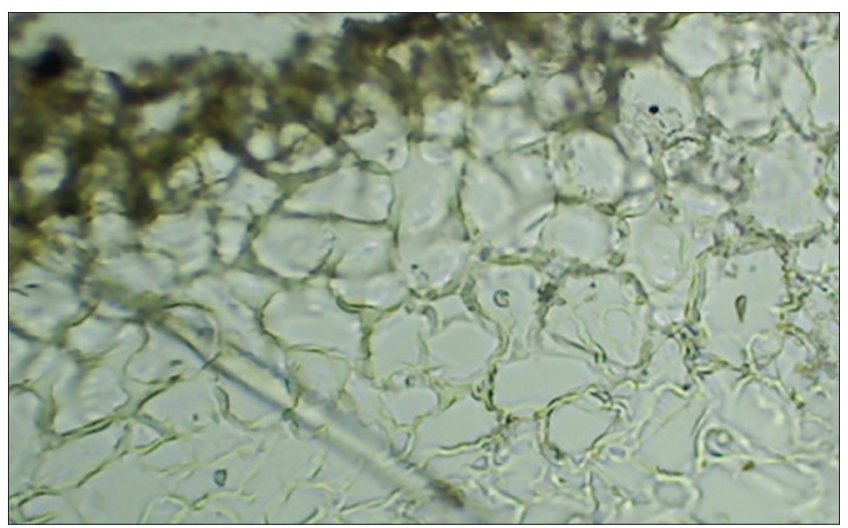

Fig. 2: Transverse section of rhizome showing pericyclic fiber in cortex

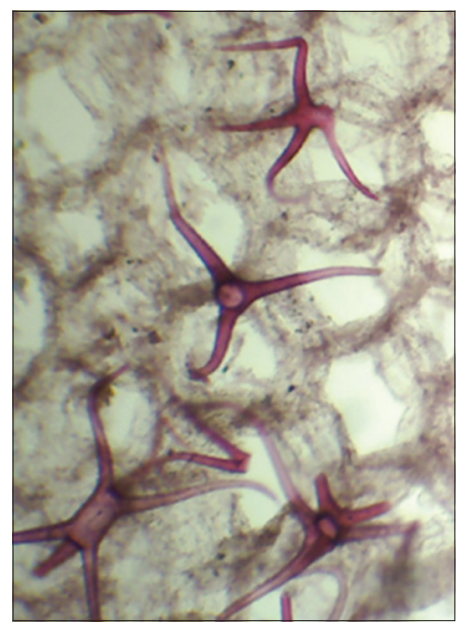

Fig. 3: Pith stained with fast green and safranin solution showing astrosclereids

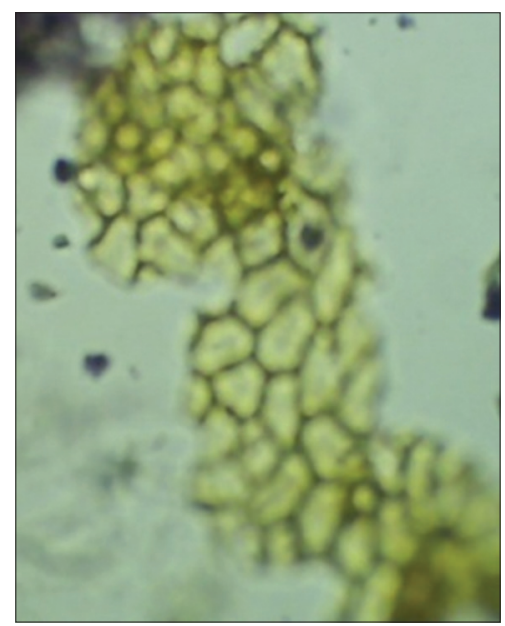

Fig. 4: Showing cork cells 


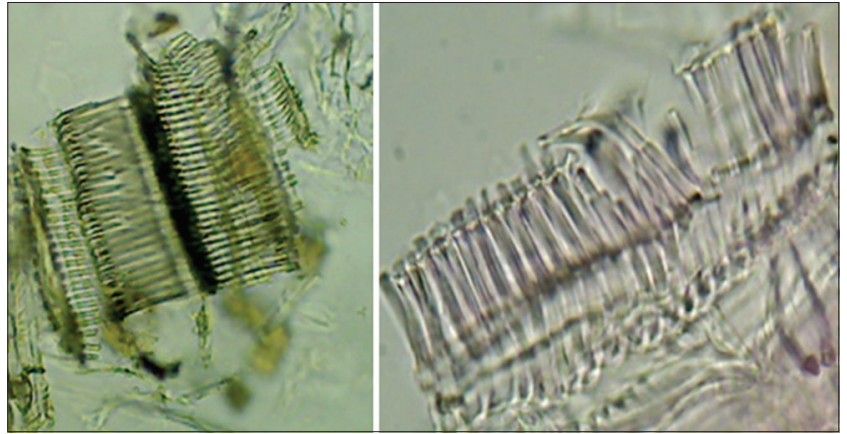

Fig. 5: Scalariform xylem vessels (simple and lignified)

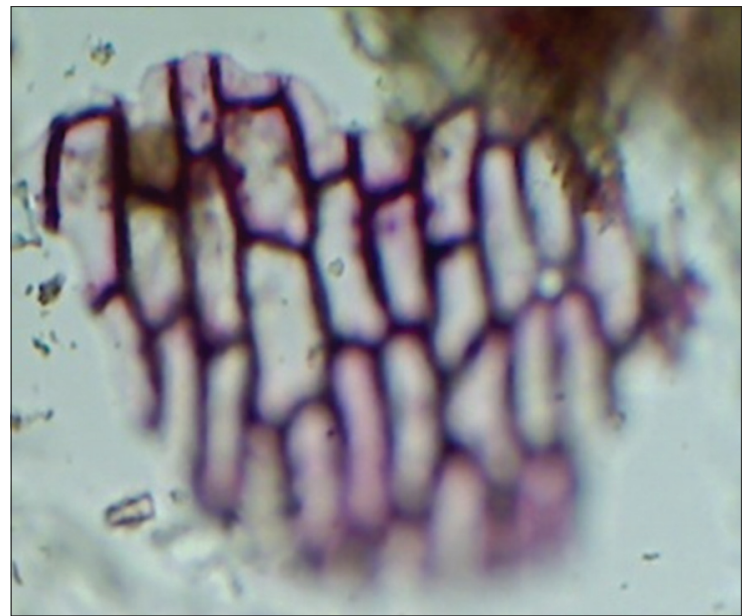

Fig. 6: Showing lignous parenchyma

The moisture content of the drug $12.5 \%$ which is tolerable thus it would discourage bacterial, fungal or yeast growth, as the general requirement for moisture content in crude drug should not be $14 \%$. The alcohol-soluble extractive value and water-soluble extractive values were found to be $32.6 \%$ and $27.6 \%$, respectively. Since the alcohol extractive value was greater than that of water, it means that alcohol is a suitable extractive solvent than water in the extraction of the rhizome powder of $N$. luteum. The alcohol and water soluble extractives are indicators of the total solvent soluble component.

\section{CONCLUSIONS}

Different pharmacognostic and physiochemical standards including macroscopy, microscopy, quantitative studies, foreign matter, ash values, extractive values, and loss on drying were generated to substantiate data on rhizomes of $N$. luteum. This study provides the detailed summary of pharmacognostical characters of rhizomes to give clear standards for the identification of drug.

\section{ACKNOWLEDGMENT}

Authors acknowledge I.K Gujral Punjab Technical University Jalandhar- Kapurthala, Punjab, for providing facilities for research.

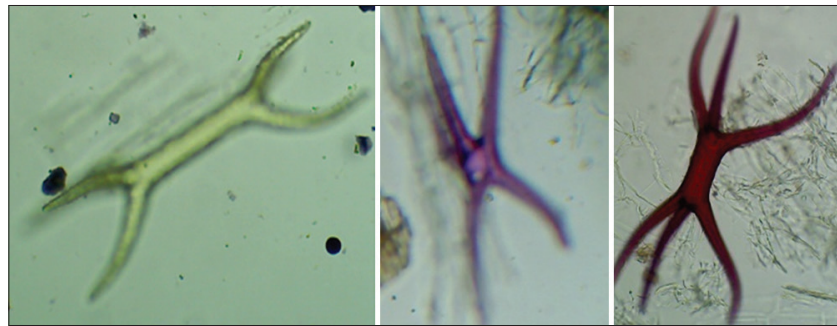

Fig. 7: Simple and lignified astrosclereids

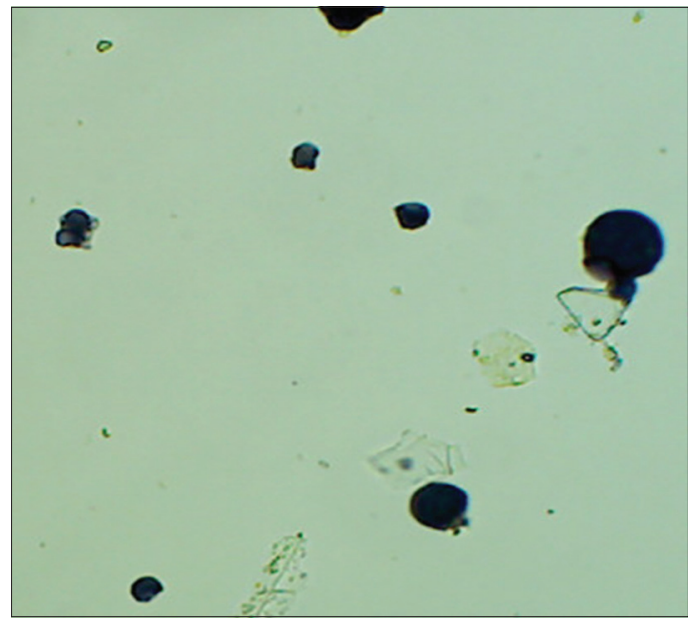

Fig. 8: Ovoid or rounded starch grains

\section{REFERENCES}

1. USDA. Germplasm Resources Information Network. Beltsville: Germplasm Resources Laboratory; 2002.

2. L1' inskaya TN, Kuzovkov AD, Monakhova TG. Alkaloids from Nuphar luteum. Chem Nat Compd 1967;3(3):147-9.

3. Brain KR, TurnerTD. The Practical Evaluation of Phytopharmaceuticals. Bristol: Wright-Scientechnica; 1975.

4. Saini S, Dhiman A, Nanda S. Pharmacognostical and phytochemical studies of Piper betle Linn leaf. Int J Pharm Pharm Sci 2016;8(5):222-6.

5. Ali I, Rhizwani GH, Shreef H, Khan S. Pharmacognostic studies of Dalbergia sisoo Roxb. Int J Pharm Pharm Sci 2016;8(12):48-53.

6. Mukherjee PK. Morphological examinations. Quality Control of Herbal Drugs. New Delhi: Business Horizon's Pharmaceutical Publishers; 2002. p. 131-47.

7. Johansen DA. Plant Microtechnique. $1^{\text {st }}$ ed. New York and London: McGraw-Hill Book Co., Inc.; 1940.

8. Anonymous. The Indian Pharmacopoeia. New Delhi: Government of India Publication; 1940

9. Anonymous. Quality Control Methods for Medicinal Plant Materials. Geneva: Organization Mondiale De La Sante; 1996.

10. Evans WC. Morphological and microscopical examinations of drugs. Trease and Evans Pharmacognosy. 15 $5^{\text {th }}$ ed. London: Saunders Ltd.; 2003. p. 516-37.

11. Ali M. Text Book of Pharmacognosy. New Delhi: CBS Publishers \& Distributers; 2008

12. Maji JK, Janani H, Patel B. Standardisation of the anticonvulsant polyherbal formulation by pharmacognostical, DNA fingerprinting and high-performance thin layer chromatography combined with chemometrics. Int J Curr Pharm Res 2017;9(1):50-8. 